\title{
DNA topology and adaptation of Salmonella typhimurium to an intracellular environment
}

\author{
David G. Marshall ${ }^{1}$, Frances Bowe ${ }^{2}$, Ghristine Hale ${ }^{2}$, Gordon Dougan ${ }^{2}$ \\ and Charles J. Dorman ${ }^{1 *}$ \\ ${ }^{1}$ Department of Microbiology, Moyne Institute of Preventive Medicine, University of Dublin, Trinity College, Dublin 2, \\ Republic of Ireland \\ ${ }^{2}$ Department of Biochemistry, Imperial College of Science, Technology and Medicine, Imperial College Road, South Kensington, \\ London SW7 2AY, UK
}

\begin{abstract}
The expression of genes coding for determinants of DNA topology in the facultative intracellular pathogen Salmonella typhimurium was studied during adaptation by the bacteria to the intracellular environment of J774A.1 macrophage-like cells. A reporter plasmid was used to monitor changes in DNA supercoiling during intracellular growth. Induction of the $d p s$ and $s p v$ genes, previously shown to be induced in the macrophage, was detected, as was expression of genes coding for DNA gyrase, integration host factor and the nucleoid-associated protein H-NS. The topA gene, coding for the DNA relaxing enzyme topoisomerase I, was not induced. Reporter plasmid data showed that bacterial DNA became relaxed following uptake of S.typhimurium cells by the macrophage. These data indicate that DNA topology in S.typhimurium undergoes significant changes during adaptation to the intracellular environment. A model describing how this process may operate is discussed.
\end{abstract}

Keywords: intracellular growth; DNA topology; gene expression; adaptation; Salmonella typhimurium

\section{INTRODUCTION}

Bacterial adaptation to stressful environments is the subject of intense investigation at present and studies performed in vitro have helped to identify many of the components used by prokaryotes to survive when under stress. Much of this work has been carried out with the facultative intracellular pathogen, Salmonella typhimurium (see §5). The central importance of gene regulation to stress responses is obvious and a great deal of detailed information is available about the processes that control gene expression at the transcriptional and post-transcriptional levels. Almost all of this information has been acquired through work with the bacteria under in vitro conditions, although attempts have been made to extrapolate from the in vitro work to the in vivo situation. The recent development of techniques that permit stress responses to be studied directly in the in vivo situation has accelerated the pace of this field.

An overview of gene regulatory processes reveals controls that operate at a 'local' level (to regulate individual promoters, etc.) and others that play a more general or 'global' role. This report deals with regulatory mechanisms of the latter class. It is concerned with determinants of the topology of bacterial DNA, each of which has been shown in vitro to be capable of modulating the transcriptional profile of the cell. These are DNA gyrase, a type II topoisomerase that introduces negative supercoils into DNA, an activity that is unique to prokaryotes; DNA topoisomerase I, an enzyme that relaxes DNA and which

*Author for correspondence (cjdorman@tcd.ie). acts antagonistically to gyrase; integration host factor (IHF), a sequence-specific DNA-binding protein that places $180^{\circ}$ bends into DNA and modulates the function of many bacterial promoters, as well as influencing transposition, site-specific recombination, DNA replication and other DNA transactions; H-NS, a nucleoid-associated protein that binds DNA in a sequence-independent manner (it is thought to recognize and bind at, or close to, regions of intrinsic curvature in DNA) and can regulate transcription from a large number of promoters (almost always negatively) as well as influencing other DNA reactions such as site-specific recombination. In addition to the genes coding for these global regulators, this study also encompasses two well-characterized stress response promoters, those of the plasmid-located spv virulence genes and of the chromosomally linked $d p s$ gene that expresses a DNA protection system in starved cells.

\section{DNA TOPOISOMERASES}

Gyrase is composed of two subunit proteins, GyrA and $\mathrm{GyrB}$, and has an $\mathrm{A}_{2} \mathrm{~B}_{2}$ tetrameric structure. It requires ATP to supercoil DNA negatively (Gellert et al. 1976) and this requirement links gyrase activity to the physiological state of the cell. Thus, when bacteria experience certain stresses, such as an upshift in osmolarity or a transition from aerobic to anaerobic growth, gyrase activity is altered and the result is a change in the level of supercoiling in the DNA (Dorman et al. 1988; Higgins et al. 1988; Hsieh et al. 1991a,b; Jensen et al. 1995; Van Workum et al. 1996). Supercoiling imparts free energy to DNA and 
this drives structural transitions in the DNA helix, including open complex formation at certain promoters (Drlica 1992). In this way, many promoters located in different parts of the genome can respond simultaneously to an alteration in the external environment. The promoters of the gyrase genes are supercoiling responsive. They are inhibited by increases in negative superhelicity but become induced when DNA is relaxed (Menzel \& Gellert 1983, 1987a,b). Thus, gyrase expression can respond to changes in supercoiling at the level of transcription and gyrase activity can respond to fluctuations in the [ATP]: [ADP] ratio at the level of topoisomerase activity.

Another gene with a supercoiling-sensitive promoter is topA, which codes for topoisomerase I (Tse-Dinh 1985). This monomeric type I topoisomerase relaxes DNA that has become supercoiled past a critical point (Wang 1971). It is thought that the countervailing activities of topoisomerase I and DNA gyrase establish a homeostatic supercoiling balance in the cell (DiNardo et al. 1982; Menzel \& Gellert 1983). Topoisomerase I does not have an ATP requirement and uses energy stored in the negatively supercoiled DNA to drive the DNA relaxation reaction (Drlica 1992). The topA promoter is activated when DNA supercoiling increases and is inhibited by relaxation (the opposite of the gyr gene promoters) (TseDinh 1985).

\section{INTEGRATION HOST FACTOR}

The IHF is encoded by two unlinked genes, ihf $A$ and ihfB. The protein has a heterodimeric AB structure and binds to the consensus sequence WATGAANNNNTTR (where $\mathrm{W}$ is a pyrimidine, $\mathrm{R}$ is a purine and $\mathrm{N}$ is any base). IHF binding introduces a bend of up to $180^{\circ}$ at the binding site and this is thought to be central to its biological role (Ellenberger \& Landy 1997; Rice et al. 1996; Travers 1997). It promotes long-range interactions in DNA and between proteins bound at distant sites on the same DNA molecule (Goosen \& Van de Putte 1995; Nash 1996). IHF is required for the formation of nucleoprotein complexes such as the lambda intasome (Goodman \& Nash 1989; Snyder et al. 1989) and the type 1 fimbrial invertasome (Blomfield et al. 1997; Dorman \& Higgins 1987; Eisenstein et al. 1987), both in Escherichia coli. Expression of the ihf genes is subject to complex control; they respond to growth phase, RpoS, guanosine tetraphosphate and are subject to autoregulation (Aviv et al. 1994). ( $\mathrm{RpoS}$ is an alternative sigma factor used by RNA polymerase when bacteria undergo stress (Hengge-Aronis 1996); guanosine tetraphosphate is an alarmone that is synthesized by bacteria during starvation (Cashel et al. 1996).) Furthermore, the ihf $A$ gene is part of an operon with the phenylalanine tRNA synthetase genes, pheST. Although ihfA has its own promoter, it is also subject to coregulation with pheST (Mechulam et al. 1987; Miller 1984).

\section{PROTEIN H-NS}

Protein H-NS is a component of the bacterial nucleoid. It binds to DNA and can constrain supercoils. Its oligomeric structure is a matter of disagreement in the literature, although it is probably at least tetrameric (Spurio et al. 1997). H-NS can form heteromeric complexes with a closely related paralogue, StpA (Cusick \& Belfort 1998), and this may be important for the biological roles of both proteins (Dorman et al. 1999; Zhang et al. 1996). H-NS influences the transcription of many genes. Usually it acts as a repressor and the genes under its control usually have other, specific regulators (Atlung \& Ingmer 1997; Bertin et al. 1999; Ussery et al. 1994; Williams \& Rimsky 1997). Some of these are transcription activators, which directly oppose the negative influence of H-NS (Jordi et al. 1992). H-NS-responsive genes have little in common, apart from a general contribution to the ability of the bacterium to adapt to environmental stress. The mechanism of action of H-NS is a matter of controversy, and it is likely that more than one mechanism of gene regulation is employed. In several cases an association of $\mathrm{H}-\mathrm{NS}$ binding with a region of DNA curvature has been reported (Yamada et al. 1991), but data from in vitro experiments have caused the importance of curvature in $\mathrm{H}-\mathrm{NS}$ binding to be questioned (Jordi et al. 1997).

\section{SALMONELLA TYPHIMURIUM}

S. typhimurium is a facultative intracellular pathogen and is a useful model for studying gene expression during in vivo growth (Finlay \& Falkow 1997; Gulig 1996; Jones 1997). A great deal of research has been conducted in vitro into the response of $S$.typhimurium to stress at the level of gene expression (Alpuche-Aranda et al. 1992; Foster \& Spector 1995; Groisman \& Saier 1990). Recently, this work has been extended by a number of in vivo studies using reporter gene fusions to stress-regulated promoters. These investigations have identified several genes as being activated during in vivo growth or as coding for products that are essential for survival while the bacterium is within the host (Heitoff et al. 1997; Hensel et al. 1995; Valdivia \& Falkow 1997).

Investigations performed with bacteria grown in vitro have illustrated the contributions made to stress responses by genes whose products modulate DNA topology (Dorman 1995). We wished to study the responses of these genes to intracellular growth as a first step in elucidating their involvement in bacterial adaptation to in vivo growth. The work was carried out in the murine macrophage-like J774A.1 cell line (American Type Culture Collection, Manassas, VA, USA), which has been used extensively for the study of intracellular growth (Buchmeier et al. 1993; Francis \& Gallagher 1993; Rhen et al. 1993; Uchiya et al. 1999; Wilson et al. 1997). Survival in macrophage requires the bacteria to survive several environmental assaults, including oxidative stress, acid stress and cationic peptides (Foster \& Spector 1995; Francis \& Gallagher 1993; Groisman 1994; Para-Lopez et al. 1994). The virulent SL1344 strain of S. typhimurium was used because it was fully virulent and was therefore capable of expressing all of the factors required for macrophage survival (Hoiseth \& Stocker 1981). The response of S.typhimurium to signals encountered in macrophage includes a role for the pleiotropic regulatory proteins PhoP/PhoQ. This twocomponent signal transduction system controls members of a large regulon of genes negatively or positively in response to intracellular signals (García Véscovi et al. 1996, 1997; Groisman 1994; Groisman et al. 1997; Gunn \& Miller 


\begin{tabular}{|c|c|c|c|c|}
\hline plasmid & promoter insert & insert size (bp) & $\begin{array}{l}\text { maximum reporter } \\
\text { in vitro } \mathrm{TCM}\end{array}$ & $\begin{array}{c}\text { gene induction } \\
\text { J774A.1 }\end{array}$ \\
\hline pGfp2 & & & & \\
\hline pGyrB & gyrB & 1600 & $\times 0.8 \pm 0.05$ & $\times 5.1 \pm 0.8$ \\
\hline pTopA & topA & 3300 & $\times 1.6 \pm 0.05$ & $\times 1.3 \pm 0.1$ \\
\hline pPheST & pheST-ihfA & 4700 & $\times 1.2 \pm 0.08$ & $\times 5.7 \pm 1.0$ \\
\hline pIhfA & ihfA & 860 & $\times 1.1 \pm 0.01$ & $\times 6.7 \pm 0.8$ \\
\hline pIhfB & $\operatorname{ihfB}$ & 4000 & $\times 0.6 \pm 0.04$ & $\times 2.8 \pm 0.3$ \\
\hline pHns & hns & 1600 & $\times 1.5 \pm 0.09$ & $\times 7.1 \pm 1.0$ \\
\hline pDps & $d p s$ & 714 & $\times 0.6 \pm 0.05$ & $\times 3.0 \pm 0.5$ \\
\hline $\mathrm{pSpv}$ & $s p v$ & 1574 & $\times 0.5 \pm 0.06$ & $\times 5.1 \pm 1.0$ \\
\hline
\end{tabular}

open boxes represent coding sequences of genes

Figure 1. A schematic representation of the different promoters assessed for macrophage gene expression in plasmid pGfp2 is shown (not to scale). Plasmid pGfp2 contains contiguous lac $Z$ and $g f p$ reporter genes downstream of a multiple cloning site (Marshall et al. 2000). Promoter fragments were amplified with the primer combinations detailed in table 1 (sites engineered into primers are underlined and named in parentheses). Following cleavage with restriction endonucleases the fragments were cloned into similarly cleaved pGfp2 in a direction driving reporter gene expression. Open reading frames of genes assessed are indicated by open boxes. Maximal induction levels are shown as fold increase in LacZ expression, similar induction profiles were recovered when assaying for GFP intensity (data not shown). The LacZ levels were assessed using a chemiluminesence assay as previously described (Marshall et al. 2000). GFP intensity levels were determined using a FACScan (Becton Dickenson, Oxford, UK) with argon lasers emitting at $488 \mathrm{~nm}$ and bacteria were detected by side scatter as previously described (Valdiva et al. 1996). The mean fold induction and standard deviations were calculated from a minimum of three independent experiments.

1996; Soncini \& Groisman 1996; Waldburger \& Sauer 1996). Under in vitro growth conditions, specific regulators of this type cooperate with the more global influences of DNA topology to modulate the transcriptional profile of the cell (Dorman 1995). Therefore, we wished to ascertain if determinants of DNA topology formed part of the bacterium's response to intracellular growth.

\section{6. spv AND dps GENES}

In addition to the genes involved in the regulation of DNA topology, this study included two S.typhimurium promoters shown previously to be activated in J774A.1 cells. These were from the $s p v$ and the $d p s$ genes, each of which has been studied in detail previously in vitro and in vivo (Marshall et al. 2000). The spo genes are located on a $90 \mathrm{~kb}$ virulence plasmid in the non-typhoid serovars of Salmonella (Guiney et al. 1995; Gulig 1996; Libby et al. 1997). They are required for the establishment of a systemic infection in the host and have been shown by signature-tagged mutagenesis and in vivo expression technology to be required for full virulence and to be expressed during infection (Heitoff et al. 1997; Hensel et al. 1995). The spo locus is composed of a regulatory gene, $s p v R$, coding for a LysR-like transcription activator that positively regulates both its own gene and the spvABCD operon of structural genes (Fang et al. 1991, 1992; Krause et al. 1992; Guiney et al. 1995; Pullinger et al. 1989; Sheehan \& Dorman 1998). Activation of spv transcription occurs during stationary phase in vitro and during in vivo growth (Chen et al. 1995; Kowartz et al. 1994). It requires the RpoS stress-response sigma factor, and is modulated by IHF, the leucine-responsive regulatory protein (Lrp), L-leucine, H-NS and cAMP-Crp (the latter probably acting indirectly through its effect on RpoS expression) (Marshall et al. 1999; O’Byrne \& Dorman 1994a,b; Robbe-Saule et al. 1997). In addition, spo requires a negatively supercoiled DNA template for transcription in vitro (O’Byrne \& Dorman 1994b; Marshall et al. 1999).

The $d p s$ gene is located on the bacterial chromosome, and like $s p v$, it requires the RpoS sigma factor and IHF for full expression; unlike $s p v, d p s$ is under the control of the OxyR regulator, a redox-sensitive DNA-binding protein (Altuvia et al. 1994). Dps protein is produced by starving bacteria, it co-crystallizes with the bacterial DNA and this is thought to protect the nucleic acid from damage while the bacteria are in stationary phase (Wolf et al. 1999). The $d p s$ promoter has a similar induction profile to that of spo when S. typhimurium is growing intracellularly and both promoters have been used successfully to express heterologous antigens in live attenuated vaccine strains (Marshall et al. 2000).

\section{EXPERIMENTAL RESULTS AND DISCUSSION}

Each promoter was cloned from the S.typhimurium genome by the polymerase chain reaction using standard methods, it was sequenced to ensure its structural integrity, 
Table 1. Primers $\left(5^{\prime}-3^{\prime}\right)$ used for the PCR amplification of plasmids

\begin{tabular}{|c|c|c|c|}
\hline plasmid & primer name & primer sequence & $\begin{array}{l}\text { restriction enzyme } \\
\text { recognition site }\end{array}$ \\
\hline \multirow[t]{2}{*}{ pDps } & dps up & GGGGGATGGTATATATTCTTACGGG & $($ BamHI $)$ \\
\hline & dps start & CGCGGATCGAATCTCATATCGTCTTGATG & $($ BamHI $)$ \\
\hline \multirow{2}{*}{ pTopA } & topA cds & 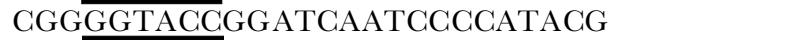 & $(\kappa p n I)$ \\
\hline & topA up2 & CGCGGATCETTTGCGGGTATGTACG ACGCG & $($ Bam HI $)$ \\
\hline \multirow{2}{*}{ pGyrB } & gyrB up & ACATGGATGCTGCTTTCACAACGAAGCG & $(S p h \mathbf{I})$ \\
\hline & gyrB start & CGGGGATCGCTTGTCGAAGCGGGCTTTCTCG & $($ BamHI $)$ \\
\hline \multirow[t]{2}{*}{ pHns } & hns up & 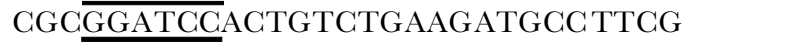 & $($ BamHI $)$ \\
\hline & hns cds & CGCGGATCCCTTCAAGGCTTTCGAGAGT AG & $($ BamHI $)$ \\
\hline \multirow[t]{2}{*}{ pPheST } & ihfA cds & 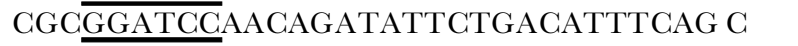 & $($ BamHI $)$ \\
\hline & ihfC & AGATGCATGGAGGCGGTCAGATGATCATGG & $(S p h \mathbf{I})$ \\
\hline \multirow[t]{2}{*}{$\mathrm{pIhfB}$} & ihfB cds & CGCGGATCCCGTCTTGGCGGGAATGTGG & $($ BamHI $)$ \\
\hline & ihfB up & CGCEGATCCTGGCACGTACAACGACGACG & $($ BamHI $)$ \\
\hline \multirow[t]{2}{*}{ pIhfA } & ihfA2 val up & CGCEGGATCGGTTTACGTTCGAGTTCAG GG & $($ Bam $\mathrm{HI})$ \\
\hline & ihfA2 val cds & 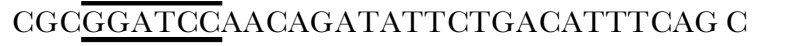 & $($ BamHI $)$ \\
\hline \multirow[t]{2}{*}{ pSpv } & spv up & CGCEGATCGAACAGGTCAATTAAATCG & $($ BamHI $)$ \\
\hline & spv cds & CCGGGATCCCCTGAAAATAAACAGAATG AAATCG & $(B a m \mathrm{HI})$ \\
\hline
\end{tabular}

a The location of the site in the primer sequence is shown by underlining.

and then fused to promoterless copies of the $g f p$-M2 gene from Aequorea victoria (Cormack et al. 1996) and the lacZ reporter gene from $E$. coli, carried in the low copy number plasmid pQF50 (Farinha \& Kropinski 1990) derivative, pGfp2 (figure 1). This plasmid offered two reporters, green fluoresence encoded by $g f p$ and $\beta$-galactosidase encoded by lac $Z$. In the experiments described here, data obtained from monitoring lacz expression are presented (figure 2), although all of the results were validated by $g f p$ expression (data not shown). S. typhimurium is naturally deficient in the lacZ gene so it was possible to monitor the levels of its product, $\beta$-galactosidase, from pGfp2 derivatives harboured in SL1344 strains while these were growing in vitro or in vivo. $\beta$-galactosidase expression was measured using the chemiluminescent substrate Galacton Star (Clontech, Basingstoke, UK). The cloning strategy and the standard $\beta$-galactosidase assay employed have been described elsewhere (Marshall et al. 2000). Details of individual plasmid constructions are summarized in figure 1.

J774A.1 macrophage-like cells grown in tissue culture medium (TCM) were infected with SL1344 bacteria at a ratio of ten bacteria per macrophage. Following infection, treatment with gentamycin $\left(20 \mu \mathrm{g} \mathrm{ml}^{-1}\right)$ was used to kill bacteria that had not been engulfed by the J774A.1 cells. Procedures for the growth of J774A.1 and SL1344 cells and the monitoring of in vivo gene expression have been described elsewhere (Marshall et al. 2000). The bacteria were also inoculated into macrophage-free TCM to determine background levels of gene expression.

Topoisomer analysis of reporter plasmid supercoiling was used to determine the effects of intracellular growth on DNA topology. The multicopy plasmid pUC18 was introduced into strain SL1344 and this strain was used to infect J774A.1 macrophage-like cells. The pUC18 DNA was recovered from the infected cells and examined electrophoretically for changes in supercoiling. Due to the low yield of plasmid DNA from the intracellular bacteria, the chloroquine-agarose gels were hybridized with a digoxygenin-labelled pUCl8 probe using the labelling and detection procedures of Free \& Dorman (1997). For electrophoresis in one dimension, gels contained $2.5 \mu \mathrm{g} \mathrm{ml}^{-1}$ chloroquine; under these conditions those topoisomers that had been more supercoiled in the bacteria migrated fastest in the gel (figure 3). For electrophoresis in a second dimension, the topoisomers were passed through a gel containing $20 \mu \mathrm{g} \mathrm{ml}^{-1}$ chloroquine. Here, topoisomers that were more relaxed in the first dimension formed an arc of positively supercoiled topoisomers migrating above the arc of negatively supercoiled topoisomers (Higgins et al. 1988; Wu et al. 1988) (figure 3).

Plasmid DNA isolated from S. typhimurium SL1344 cells that had been incubated in TCM alone showed a broad distribution of topoisomers similar to that seen in extracts from bacteria grown in standard laboratory media (Dorman et al. 1988; Higgins et al. 1988) and this distribution varied by just one or two topoisomers over time (figure $3 b$ ). In contrast, plasmid DNA removed from SL1344 that had infected J774A.1 macrophage-like cells showed a distribution that became progressively relaxed with time and included a novel fast-migrating species that increased in intensity with time spent in the macrophage (figure 3a). Electrophoresis with different concentrations of the chloroquine intercalator and twodimensional electrophoresis (figure $3 c$ ) showed that this species was composed of positively supercoiled DNA, i.e. plasmid DNA that had been highly relaxed in the bacteria.

The discovery that in vivo growth led to the production of a population of highly relaxed plasmids raised the possibility that bacterial DNA lost negative supercoils as a result of life within the macrophage. This finding is analogous to the effect of starvation on bacteria grown in vitro (Balke \& Gralla 1987) and normally elicits a response at the level of gene transcription. In particular, genes required to compensate for the change in DNA topology might have been expected to have been induced, whereas genes whose products are unhelpful would not. We studied the response to intracellular growth of a panel of S.typhimurium promoters likely to be involved in adaptation to DNA relaxation. 

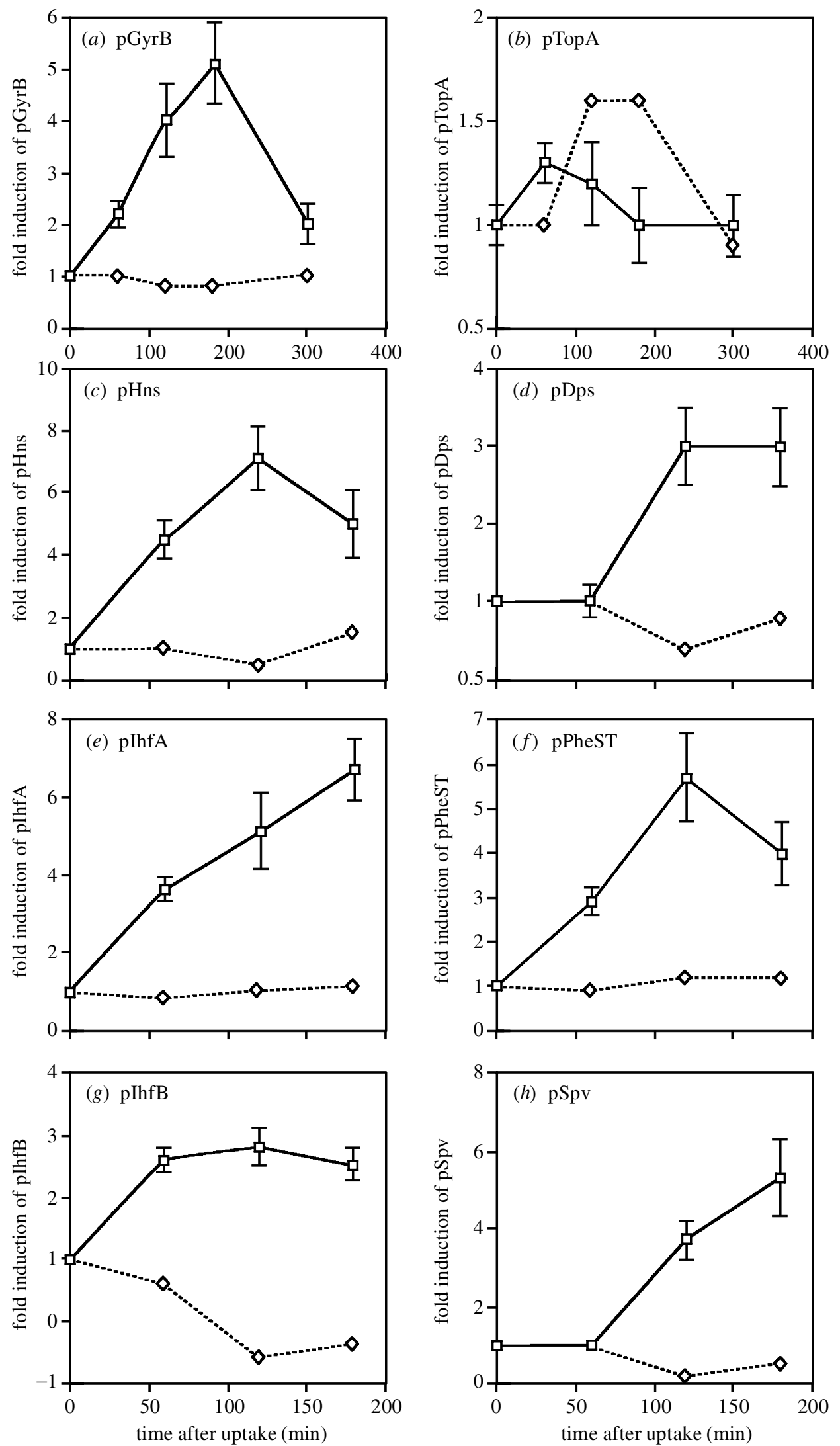

Figure 2. Induction kinetics for S. typhimurium promoters studied in vivo following uptake by J774A.1 macrophages. Macrophage infection and LacZ assays were performed as described previously (Marshall et al. 2000). $\beta$-galactosidse activity was expressed as light units released per viable bacterium (light units per colony forming unit) following infection relative to the activity in the inoculum sample, and is the mean of at least three independent experiments for studies with J774A. 1 cells. Squares, data points for intracellular bacteria; diamonds, data points for bacteria in TGM alone. 
(10)

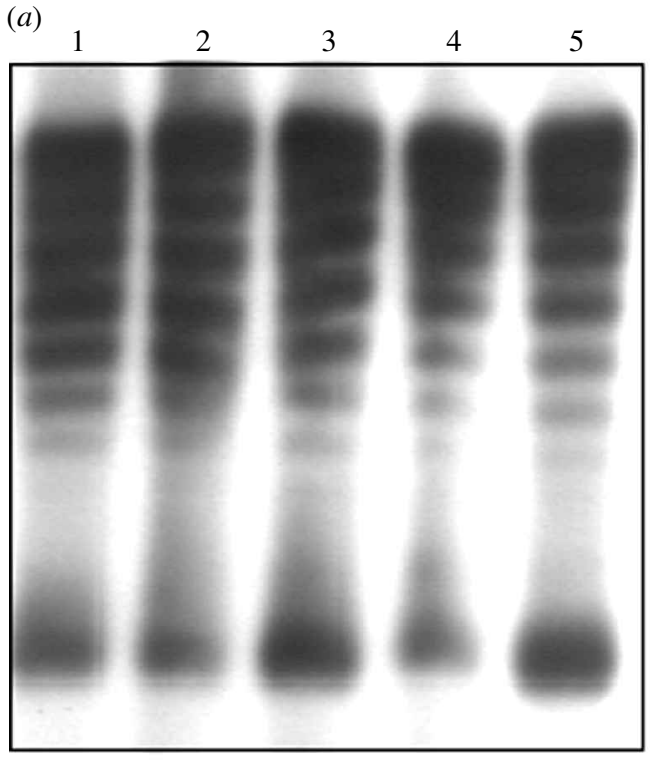

(b)

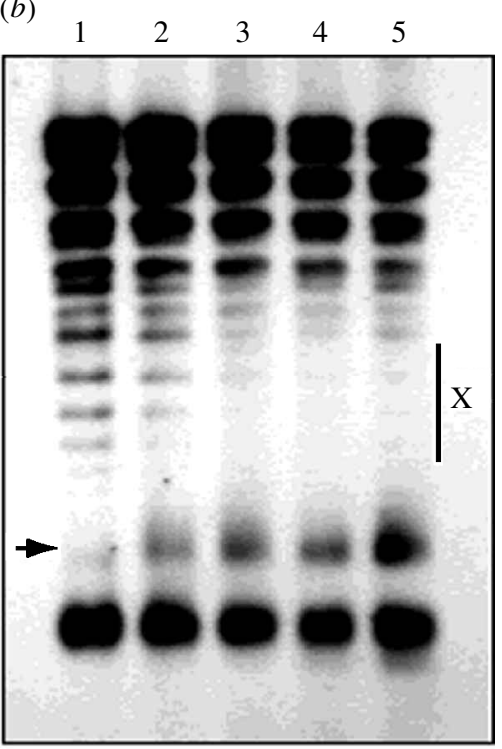

(c)

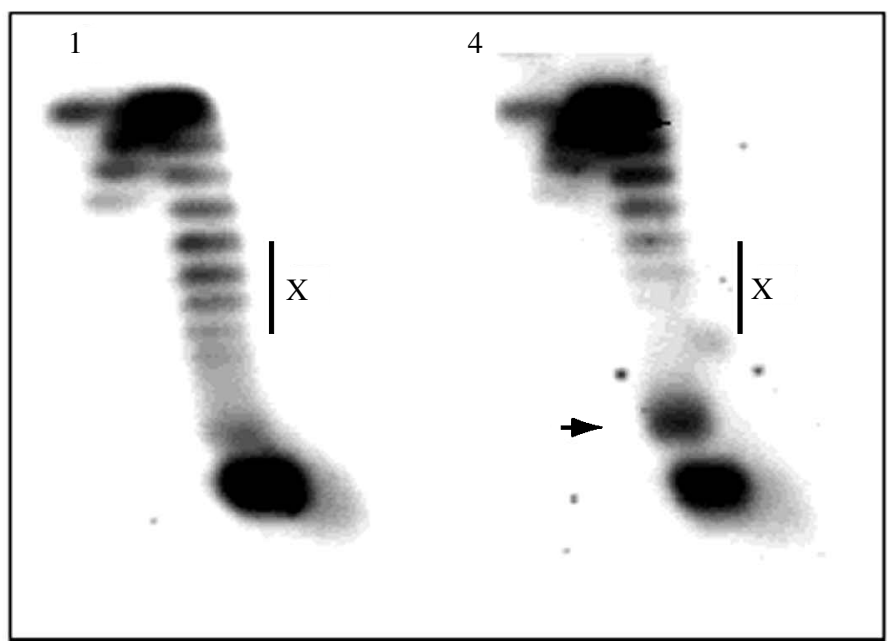

Figure 3. DNA supercoiling in intracellularly grown S.typhimurium. $(a, b)$ One-dimensional agarose gel electrophoresis through $1 \%(\mathrm{w} / \mathrm{v})$ agarose gel in $1 \times$ tris borate $(\mathrm{TBE})$ containing $2.5 \mathrm{mg}$ chloroquine $\mathrm{ml}^{-1}$. Topoisomer distribution in inoculum sample (lanes 1); after $40 \mathrm{~min}$ (lanes 2); after $80 \mathrm{~min}$ (lanes 3); after $120 \mathrm{~min}$ (lanes 4); after $180 \mathrm{~min}$ (lanes 5). (a) Topoisomer distribution of pUC18 following incubation of SL1344(pUC18) in TCM in $5 \% \mathrm{CO}_{2}$ at $37^{\circ} \mathrm{C}$. (b) Topoisomer distribution of plasmid pUC18 before and following infection of macrophages with SL1344(pUC18). (c) Two-dimensional agarose gel electrophoresis

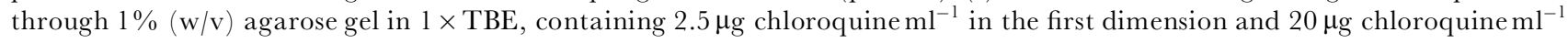
in the second dimension. Sample 1, pUC18 topoisomer distribution in S.typhimurium inoculum sample (corresponds to lane 1 of $b$ ); Sample 4, pUC18 topoisomer distribution in S. typhimurium following infection of J774A.1 macrophages for 120 min (corresponds to lane 4 of $b$ ). The distribution of more negatively supercoiled topoisomers present in the inoculum but absent in the intracellular bacteria is highlighted $(\mathrm{X})$ in $b$ and $c$. The novel fast migrating species unique to the intracellularly recovered bacteria is arrowed in $b$ and $c$.

DNA gyrase would be expected to play a prominent role in the restoration of lost negative supercoiling. To do this it would require an upward shift in the [ATP]: [ADP] ratio. Even in the absence of sufficient ATP (as in starving cells) to allow gyrase to function in negative supercoiling, the gyr gene promoters would be expected to be induced directly by DNA relaxation. In TCM alone, the $\operatorname{gyr} B$ promoter showed no induction during a $180 \mathrm{~min}$ incubation. In contrast, it was induced by approximately fivefold when the bacteria were inside macrophage for the same period (figure 1). This was in agreement with the known behaviour of the equivalent promoter from E. coli when studied in vitro (Menzel \& Gellert 1983, 1987a,b). In contrast, the promoter for the topA gene (encoding the
DNA relaxing enzyme topoisomerase I) showed no induction in TCM or in macrophage (figure 1). Since the topA promoter from E. coli is known to be inhibited by DNA relaxation, this finding was in keeping with the plasmid topoisomer data described above.

Other studies have suggested that the IHF may play a role in maintaining DNA topology in a form favourable to certain promoters under conditions where a general DNA relaxation takes place (Porter \& Dorman 1997). In vitro, this relaxation occurs in stationary phase, and IHF levels have been shown to increase during this period of the growth curve, at least in E. coli (Ditto et al. 1994). An earlier study had shown that one of the genes coding for IHF, the ihfA gene (designated mig-23 for 'macrophage-inducible 
gene 23'), was possibly induced when S.typhimurium grows intracellularly (Valdivia \& Falkow 1987). In that study, the recombinant plasmid tested contained just a segment of the pheT gene where the ihfA promoter was located; it had not included the complete pheST operon and its promoter as well as that of $i h f A$. We constructed a plasmid that included the complete pheST-ihfA operon and obtained an approximately fivefold induction in the J774A.l cells with no induction in TGM alone (figure 1). To resolve the issue of the possible contribution of the pheST promoter, a derivative plasmid was made in which the expression of the reporter genes was under the control of the ihf $A$ promoter alone. The data obtained with this plasmid showed that ihf $A$ was induced approximately sixfold during intracellular growth but not in TCM alone (figure 1). This shows that the ihf A promoter responds to growth in macrophage and this response is not modulated by a contribution from the pheST promoter. The promoter from the ihfB gene was also tested and found to be inducible intracellularly but not in growth medium alone (figure 1). (The response of the ihfB promoter to intracellular growth had not been assessed previously.) These data for ihf gene expression are in keeping with results obtained from in vitro studies showing that these genes are induced when bacteria are starved or undergo environmental stress (Aviv et al. 1994; Ditto et al. 1994).

Successful establishment of an infection requires the bacterium to multiply in the intracellular state (Finlay \& Falkow 1997). Previous work performed in vitro with E.coli has shown that expression of the nucleoid-associated protein H-NS is coupled to DNA synthesis such that in rapidly growing bacteria the hns gene is induced while in quiescent cells it is repressed (Free \& Dorman 1995). The hns promoter was induced strongly in S.typhimurium cells growing in macrophage and not induced in TCM alone (figure 1). This suggests that while the bacteria may have been stressed when associated with the J774A.1 cells, they were still able to operate an efficient cell cycle, thus creating a demand for hns gene expression. A previous study has indicated that intracellular S.typhimurium cells grow rapidly and require protein synthesis for survival. As the bacteria adapt to the intracellular environment of the macrophage, they switch from this rapid growth mode to a survival state that does not require protein synthesis (Abshire \& Neidhardt 1993). The kinetics of hns induction revealed here, with expression declining $2 \mathrm{~h}$ post-infection (figure 2), concurs with the findings of this earlier study.

As positive controls for the experiments described here, the $d p s$ and spv promoters were also studied. Each had been shown previously to be induced during intracellular growth (Marshall et al. 2000) and induction was also detected in this study (figures 1 and 2).

This study addresses a specific aspect of bacterial physiology during infection, namely what are the consequences of the infection process for the topology of bacterial DNA and for the expression of genes coding for proteins that modulate DNA topology? It appears that infection of the J774A.1 cell line causes bacterial DNA to become relaxed. As one might predict, the relaxationinhibited promoter of the top $A$ gene remains repressed under these conditions. In contrast, the $\operatorname{gyr} B$ gene, coding for one of the subunits of DNA gyrase, is induced strongly.
This is consistent with the production of extra copies of gyrase to restore supercoiling levels to values favourable to most DNA-based molecular transactions. The level of gyr $B$ expression declines after $3 \mathrm{~h}$, suggesting that by this stage post-infection supercoiling is restored at the $\operatorname{gyr} B$ promoter (figure 2).

The spo promoter used in this study illustrates some of the complexities arising from our data. It is supercoiling responsive and has been shown previously to be inhibited when DNA becomes relaxed (Marshall et al. 1999). However, in vitro data show that this inhibition requires the IHF protein; in the absence of this accessory factor, spv expression remains high even when DNA is relaxed (Marshall et al. 1999). This points to a subtle interplay between IHF and gyrase in the regulation of spv transcription. The in vivo data presented here show that spv is induced when the global level of DNA supercoiling is low. This may point to a shortage of IHF in vivo (consistent with the strong induction of the genes that code for this protein) or simply point to additional complexities inherent in the in vivo situation. For example, the leucineresponsive regulatory protein (Lrp) also regulates spo expression in vitro (Marshall et al. 1999) and this may have a positive modulatory influence when the bacterium is growing in association with macrophage. Alternatively, the negative influence of H-NS on spo expression described previously in vitro (O'Byrne \& Dorman 1994b; Robbe-Saule et al. 1997) may not operate under the in vivo conditions studied here, and this is consistent with our data on hns gene induction in macrophage (figures 1 and 2) suggesting that not all H-NS-binding sites in the bacterial genome are occupied.

The data presented here allow a tentative model to be advanced to describe early events in intracellular adaptation from the perspective of DNA topology. Three lines of evidence suggest that DNA becomes relaxed early in the process. These are a direct observation of reporter plasmid topology by electrophoresis in the presence of a DNA intercalator, the positive response of the DNA relaxation-activated $\operatorname{gyr} B$ promoter, and the lack of a response from the DNA relaxation-inhibited topA promoter. Why does the DNA become relaxed? The most likely explanation is that the negative supercoiling activity of bacterial gyrase is inhibited as a result of interactions with the mammalian cells. This could arise from an unfavourable shift in the $[\mathrm{ATP}]:[\mathrm{ADP}]$ ratio. As ATP levels fall and ADP levels rise, the negative supercoiling activity of gyrase is inhibited, although it can continue to contribute to ATP-independent relaxation of DNA (Drlica 1992). DNA topoisomerase I, and to some extent the other two topoisomerases in the cell, might also be expected to contribute to the general relaxation of genomic DNA. The induction of the genes encoding IHF may be regarded as a mechanism for dealing selectively with unfavourable alterations in DNA topology. Those promoters with appropriately located IHF-binding sites (such as spv) may be protected from inhibition as the DNA relaxes through the creation of a nucleoprotein complex that preserves promoter function. Other IHFdependent processes, such as DNA replication, transposition and site-specific recombination, may also continue to function. Other evidence suggesting that DNA replication continues under the conditions of our experiments comes 
from the observation of hns gene expression. A demand for hns transcription has been shown in vitro to be created by DNA synthesis (Free \& Dorman 1995) and the in vivo data presented here suggest that this process operates during the macrophage infection. This is consistent with the data of Abshire \& Neidhardt (1993) showing that vigorous protein synthesis occurs for approximately $2 \mathrm{~h}$ following macrophage engulfment of S.typhimurium. The overall picture that emerges is one of stressed bacteria with abnormally relaxed levels of DNA supercoiling that continue to grow and express genes that are critical for adaptation to this environment. This situation is in marked contrast to that described for invasion of epithelia by S.typhimurium. Their increased negative supercoiling is an essential prerequisite for expression of invasion functions (Galán \& Curtiss 1990). Thus, DNA topology contributes to different types of host-pathogen interaction, and it does so in a dynamic way. Understanding how transitions between the different phases of the infection affect DNA topology and gene expression will form the next phase of the work.

This work was supported by a grant (BIO4-CT96-0144) from the European Union.

\section{REFERENCES}

Abshire, K. Z. \& Neidhardt, F. C. 1993 Growth rate paradox of Salmonella typhimurium within host macrophages. F. Bacteriol. 175, 3744-3748.

Alpuche-Aranda, C. M. A., Swanson, J. A., Loomis, W. P. \& Miller, S. I. 1992 Salmonella typhimurium activates virulence gene transcription within acidified macrophage phagosomes. Proc. Natl Acad. Sci. USA 89, 10 079-10 083.

Altuvia, S., Almirón, M., Huisman, G., Kolter, R. \& Storz, G. 1994 The $d p s$ promoter is activated by OxyR during growth and by IHF and $\sigma^{\mathrm{s}}$ in stationary phase. Mol. Microbiol. 13, 265-272.

Atlung, T. \& Ingmer, H. 1997 H-NS: a modulator of environmentally-regulated gene expression. Mol. Microbiol. 24, 7-17.

Aviv, M., Giladi, H., Schreiber, G., Oppenheim, A. B. \& Glaser, G. 1994 Expression of the genes coding for the Escherichia coli integration host factor are controlled by growth phase, rpoS, ppGpp and by autoregulation. Mol. Microbiol. 14, 1021-1031.

Balke, V. L. \& Gralla, J. D. 1987 Changes in linking number of supercoiled DNA accompany growth transitions in Escherichia coli. F. Bacteriol. 169, 4499-4506.

Bertin, P., Benhabiles, N., Krin, E., Laurent-Winter, C., Tendeng, C., Turlin, E., Thomas, A., Danchin, A. \& Brasseur, R. 1999 The structural and functional organization of the HNS-like proteins is evolutionarily conserved in Gram-negative bacteria. Mol. Microbiol. 31, 319-329.

Blomfield, I. C., Kulasekara, D. H. \& Eisenstein, B. I. 1997 Integration host factor stimulates both FimB- and FimEmediated site-specific DNA inversion that controls phase variation of type 1 fimbriae in Escherichia coli. Mol. Microbiol. 23, 705-717.

Buchmeier, N. A., Lipps, C. J., So, M. Y. \& Heffron, F. 1993 Recombination-deficient mutants of Salmonella typhimurium are avirulent and sensitive to the oxidative burst of macrophages. Mol. Microbiol. 7, 933-936.

Cashel, M. Gentry, D. R., Hernandez, V. J. \& Vinella, D. 1996 The stringent response. In Escherichia coli and Salmonella: cellular and molecular biology (ed. F. C. Neidhardt, R. Curtiss III, J. L. Ingraham, E. C. C. Lin, K. B. Low, B. Magasanik,
W. S. Reznikoff, M. Riley, M. Schaechter \& H. E. Umbarger), pp. 1458-1496. Washington, DC: American Society for Microbiology.

Chen, G.-Y., Eckmann, L., Libby, S. J., Fang, F. C., Okamoto, S., Kagnoff, M. F., Fierer, J. \& Guiney, D. G. 1996 Expression of Salmonella typhimurium rpoS and rpoS-dependent genes in the intracellular environment of eukaryotic cells. Infect. Immun. 64, 4739-4743.

Cormack, B. P., Valdivia, R. H. \& Falkow, S. 1996 FACS-optimized mutants of the green fluorescent protein (GFP). Gene 173, 33-38.

Cusick, M. E. \& Belfort, M. 1998 Domain structure and RNA annealing activity of the Escherichia coli regulatory protein StpA. Mol. Microbiol. 28, 847-857.

DiNardo, S., Voekel, K. A., Sternglanz, R., Reynolds, A. E. \& Wright, A. 1982 Escherichia coli DNA topoisomerase I mutants have compensatory mutations in DNA gyrase genes. Cell 31, $43-51$.

Ditto, M. D., Roberts, D. \& Weisberg, R. A. 1994 Growth phase variation of integration host factor level in Escherichia coli. $\mathcal{F}$. Bacteriol. 176, 3738-3748.

Dorman, C. J. 1995 DNA topology and the globasl control of bacterial gene expression: implications for the regulation of virulence gene expression. Microbiology 141, 1271-1280.

Dorman, C. J. \& Higgins, C. F. 1987 Fimbrial phase variation in Escherichia coli: dependence on integration host factor and homologies with other site-specific recombinases. F. Bacteriol. 169, 3840-3843.

Dorman, G. J., Barr, G. C., Ní Bhriain, N. \& Higgins, G. F. 1988 DNA supercoiling and the anaerobic and growth phase regulation of tonB gene expression. F. Bacteriol. 170, 2816-2826.

Dorman, G. J., Hinton, J. C. D. \& Free, A. 1999 Homo- and hetero-oligomerization among H-NS-like nucleoid-associated proteins in bacteria. Trends Microbiol. 7, 124-128.

Drlica, K. 1992 Control of bacterial DNA supercoiling. Mol. Microbiol. 6, 425-433.

Eisenstein, B. I., Sweet, D. S., Vaughn, V. \& Friedman, D. I. 1987 Integration host factor is required for the DNA inversion that controls phase variation in Escherichia coli. Proc. Natl Acad. Sci. USA 84, 6506-6510.

Ellenberger, T. \& Landy, A. 1997 A good turn for DNA: the structure of integration host factor bound to DNA. Structure 5, $153-157$.

Fang, F. C., Krause, M., Roudier, C., Fierer, J. \& Guiney, D. G. 1991 Growth regulation of a Salmonella plasmid gene essential for virulence. 7. Bacteriol. 173, 6783-6789.

Fang, F. C., Libby, S. J., Buchmeier, N. A., Loewen, P. C., Switala, J., Harwood, J. \& Guiney, D. G. 1992 The alternative sigma factor KatF (RpoS) regulates Salmonella virulence. Proc. Natl Acad. Sci. USA 89, 11 978-11 982.

Farinha, M. A. \& Kropinski, A. M. 1990 Construction of broad-host-range plasmid vectors for easy visible selection and analysis of promoters. F. Bacteriol. 172, 3496-3499.

Finlay, B. B. \& Falkow, S. 1997 Common themes in microbial pathogenicity revisited. Microbiol. Mol. Biol. Rev. 61, 136-169.

Foster, J. W. \& Spector, M. P. 1995 How Salmonella survive against the odds. A. Rev. Microbiol. 49, 145-174.

Francis, K. P. \& Gallagher, M. P. 1993 Light emission from a mud-lux transcriptional fusion in Salmonella typhimurium is stimulated by interaction with the mouse macrophage cell line J774.2. Infect. Immun. 61, 640-649.

Free, A. \& Dorman, C. J. 1995 Coupling of Escherichia coli hns mRNA levels to DNA synthesis by autoregulation: implications for growth phase control. Mol. Microbiol. 18, 101-113.

Free, A. \& Dorman, C. J. 1997 The Escherichia coli stpA gene is transiently expressed during growth in rich medium and is induced in mimimal medium and by stress conditions. $\mathcal{F}$. Bacteriol. 179, 909-918. 
Galán, J. E. \& Curtiss, R. 1990 Expression of Salmonella typhimurium genes required for invasion is regulated by changes in DNA supercoiling. Infect. Immun. 58, 1879-1885.

García Véscovi, E., Soncini, F. C. \& Groisman, E. A. $1996 \mathrm{Mg}^{2+}$ as an extracellular signal: environmental regulation of Salmonella typhimurium. Cell 84, 165-174.

García Véscovi, E., Ayala, Y. M., Di Cera, E. \& Groisman, E. A. 1997 Characterization of the bacterial sensor protein PhoQ. Evidence for distinct binding sites for $\mathrm{Mg}^{2+}$ and $\mathrm{Ca}^{2+}$. F. Biol. Chem. 272, 1440-1443.

Gellert, M., Mizuuchi, K., O’Dea, M. H. \& Nash, H. A. 1976 DNA gyrase: an enzyme that introduces superhelical turns into DNA. Proc. Natl Acad. Sci. USA 73, 3872-3876.

Goodman, S. D. \& Nash, H. A. 1989 Functional replacement of a protein-induced bend in a DNA recombination site. Nature 341, 251-254.

Goosen, N. \& Van de Putte, P. 1995 The regulation of transcription initiation by integration host factor. Mol. Microbiol. 16, 1-7.

Groisman, E. A. 1994 How bacteria resist killing by hostdefense peptides. Trends Microbiol. 2, 444-449.

Groisman, E. A. 1998 The ins and outs of virulence gene expression: $\mathrm{Mg}^{2+}$ as a regulatory signal. BioEssays 20, 96-101.

Groisman, E. A. \& Saier, M. H. 1990 Salmonella virulence: new clues to intracellular survival. Trends Biochem. Sci. 15, 30-33.

Groisman, E. A., Kayser, J. \& Soncini, F. C. 1997 Regulation of polymyxin resistance and adaptation to low- $\mathrm{Mg}^{2+}$ environments. F. Bacteriol. 179, 7040-7045.

Guiney, D. G., Libby, S., Fang, F. C., Krause, M. \& Fierer, J. 1995 Growth-phase regulation of plasmid virulence genes in Salmonella. Trends Microbiol. 3, 275-279.

Gulig, P. A. 1996 Pathogenesis of systemic disease. In Escherichia coli and Salmonella: cellular and molecular biology (ed. F. C. Neidhardt, R. Curtiss III, J. L. Ingraham, E. C. C. Lin, K. B. Low, B. Magasanik, W. S. Reznikoff, M. Riley, M. Schaechter \& H. E. Umbarger), pp. 2774-2787. Washington, DC: American Society for Microbiology.

Gunn, J. S. \& Miller, S. I. 1996 PhoP-PhoQ activates transcription of pmrAB, encoding a two-component regulatory system involved in Salmonella typhimurium antimicrobial peptide resistance. F. Bacteriol. 178, 6857-6864.

Heitoff, D. M., Conner, C. P., Hanna, P. C., Julio, S. M., Hentschel, U. \& Mahan, M. J. 1997 Bacterial infection as assessed by in vitro gene expression. Proc. Natl Acad. Sci. USA 94, 934-939.

Hengge-Aronis, R. 1996 Regulation of gene expression during entry into stationary phase. In Escherichia coli and Salmonella: cellular and molecular biology (ed. F. C. Neidhardt, R. Curtiss III, J. L. Ingraham, E. C. C. Lin, K. B. Low, B. Magasanik, W. S. Reznikoff, M. Riley, M. Schaechter \& H. E. Umbarger), pp. 1497-1512. Washington, DC: American Society for Microbiology.

Hensel, M., Shea, J. E., Gleeson, C., Jones, M. D., Dalton, E. \& Holden, D. W. 1995 Simultaneous identification of bacterial virulence genes by negative selection. Science 269, 400-403.

Higgins, C. F., Dorman, C. J., Stirling, D. A., Waddell, L. Booth, I. R., May, G. \& Bremer, E. 1988 A physiological role for DNA supercoiling in the osmotic regulation of gene expression in S. typhimurium and E. coli. Cell 52, 569-584.

Hoiseth, S. K. \& Stocker, B. A. D. 1981 Aromatic-dependent S.typhimurium are non-virulent and are effective as live vaccines. Nature 291, 238-239.

Hsieh, L.-S., Burger, R. M. \& Drlica, K. 1991a Bacterial DNA supercoiling and $[\mathrm{ATP}] /[\mathrm{ADP}]$ changes associated with a transition to anaerobic growth. F. Mol. Biol. 219, 443-450.

Hsieh, L.-S., Rouvierère-Yaniv, J. \& Drlica, K. $1991 b$ Bacterial DNA supercoiling and $[\mathrm{ATP}] /[\mathrm{ADP}]$ ratio: changes associated with salt shock. F. Bacteriol. 173, 3914-3917.

Jensen, P. R., Loman, L., Petra, B., Van der Weijden, C. \& Westerhoff, H. V. 1995 Energy buffering of DNA structure fails when Escherichia coli runs out of substrate. 7. Bacteriol. 177, 3420-3426.

Jones, B. D. 1997 Host responses to pathogenic Salmonella infection. Genes Dev. 11, 679-687.

Jordi, B. J. A. M., Dagberg, B., de Haan, A. A. M., Hamers, A. M., Van der Zeijst, B. J. A. M., Gaastra, W. \& Uhlin, B. E. 1992 The positive regulator CfaD overcomes the repression mediated by histone-like protein $\mathrm{H}-\mathrm{NS}(\mathrm{Hl})$ in the CFA/I fimbrial operon of Escherichia coli. EMBO f. 11, 2627-2632.

Jordi, B. J. A. M., Fielder, A., Burns, C. M., Hinton, J. C. D., Dover, N., Ussery, D. W. \& Higgins, C. F. 1997 DNA binding is not sufficient for H-NS-mediated repression of pro $U$ expression. 7. Biol. Chem. 272, 12 083-12 090.

Kowartz, L., Coynault, C., Robbe-Saule, V. \& Norel, F. 1994 The Salmonella typhimurium katF $(r p o S)$ gene: cloning, nucleotide sequence, and regulation of $s p v R$ and $s p v A B C D$ virulence plasmid genes. F. Bacteriol. 176, 6852-6860.

Krause, M., Fang, F. C. \& Guiney, D. G. 1992 Regulation of plasmid virulence gene expression in Salmonella dublin involves an unusual operon structure. F. Bacteriol. 174, 4482-4489.

Libby, S. J., Adams, L. G., Ficht, T. A., Allen, C., Whitford, H. A., Buchmeier, N. A., Bossie, S. \& Guiney, D. G. 1997 The spo genes on the Salmonella dublin virulence plasmid are required for severe enteritis and systemic infection in the natural host. Infect. Immun. 65, 1786-1792.

Marshall, D. G., Sheehan, B. J. \& Dorman, C. J. 1999 A role for the leucine-responsive regulatory protein and integration host factor in the regulation of the Salmonella plasmid virulence (spv) locus in Salmonella typhimurium. Mol. Microbiol. 34, 134-145.

Marshall, D. G., Hague, A., Fowler, R., del Guidice, G., Dorman, C. J., Dougan, G. \& Bowe, F. 2000 Use of the stationary phase inducible promoters, $s p v$ and $d p s$, to drive heterologous antigen expression in Salmonella vaccine strains. Vaccine 18, 1298-1306.

Mechulam, Y., Blanquet, S. \& Fayat, G. 1987 Dual level control of the Escherichia coli pheST-himA operon expression: tRNA ${ }^{\text {phe }}$ dependent attenuation and transcriptional operator-repressor control by himA and the SOS network. F. Mol. Biol. 197, 453-470.

Menzel, R. \& Gellert, M. 1983 Regulation of the genes for E. coli DNA gyrase: homeostatic control of DNA supercoiling. Cell 34, 105-113.

Menzel, R. \& Gellert, M. 1987 a Fusions of the Escherichia coli gyrA and $\operatorname{gyr} B$ control regions to the galactokinase gene are inducible by coumermycin treatment. F. Bacteriol. 169, 1272-1278.

Menzel, R. \& Gellert, M. $1987 b$ Modulation of transcription by DNA supercoiling: a deletion analysis of the Escherichia coli gyrA and gyrB promoters. Proc. Natl Acad. Sci. USA 84, 4185-4189.

Miller, H. I. 1984 Primary structure of the himA gene of Escherichia coli: homology with DNA-binding protein HU and association with the phenylalanyl-tRNA synthetase operon. Cold Spring Harbor Symp. Quant. Biol. 49, 691-698.

Nash, H. A. 1996 The HU and IHF proteins: accessory factors for complex protein-DNA assemblies. In Regulation of gene expression in Escherichia coli (ed. E. C. C. Lyn \& A. S. Lynch), pp 149-179. Austin, TX: R. G. Landes Co.

O’Byrne, C. P. \& Dorman, C. J. 1994a The spv virulence operon of Salmonella typhimurium LT-2 is regulated negatively by the cyclic AMP (cAMP)-cAMP receptor protein system. F. Bacteriol. 176, 905-912.

O'Byrne, C. P. \& Dorman, C. J. $1994 b$ Transcription of the Salmonella typhimurium spo virulence locus is regulated negatively by the nucleoid-associated protein H-NS. FEMS Microbiol. Lett. 121, 99-106.

Para-Lopez, C., Lin, R., Aspedon, A. \& Groisman, E. A. 1994 A Salmonella protein that is required for resistance to antimicrobial peptides and transport of potassium. EMBO F. 13, 3964-3972. 
Porter, M. E. \& Dorman, G. J. 1997 Positive regulation of Shigella flexneri virulence genes by integration host factor. $\mathcal{F}$. Bacteriol. 179, 6537-6550.

Pullinger, G. D., Baird, G. D., Williamson, C. M. \& Lax, A. J. 1989 Nucleotide sequence of a plasmid gene involved in the virulence of salmonellas. Nucl. Acids Res. 17, 7983.

Rhen, M., Riikonen, P. \& Taira, S. 1993 Transcriptional regulation of Salmonella enterica virulence plasmid genes in cultured macrophages. Mol. Microbiol. 10, 45-56.

Rice, P. A., Yang, S.-W., Mizuuchi, K. \& Nash, H. A. 1996 Crystal structure of an IHF-DNA complex: a protein-induced DNA U-turn. Cell 87, 1295-1306.

Robbe-Saule, V., Schaeffer, F., Kowartz, L. \& Norel, F. 1997 Relationships between H-NS, sigma S, SpvR and growth phase in the control of $s p v R$, the regulatory gene of the Salmonella dublin virulence plasmid. Mol. Gen. Genet. 256, 333-347.

Sheehan, B. J. \& Dorman, C. J. 1998 In vivo analysis of the interactions of the LysR-like regulator SpvR with the operator sequences of the $s p v A$ and $s p v R$ virulence genes of Salmonella typhimurium. Mol. Microbiol. 30, 91-105.

Snyder, U. K., Thompson, J. F. \& Landy, A. 1989 Phasing of protein-induced DNA bends in a recombination complex. Nature 341, 255-257 (erratum 342, 206).

Soncini, F. C. \& Groisman, E. A. 1996 Two-component regulatory systems can interact to process multiple environmental signals. F. Bacteriol. 178, 6796-6801.

Spurio, R., Falconi, M., Brandi, A., Pon, C. L. \& Gualerzi, C. O. 1997 The oligomeric structure of nucleoid protein H-NS is necessary for recognition of intrinsically curved DNA and for DNA bending. EMBO F. 16, 1795-1805.

Travers, A. 1997 DNA-protein interactions: IHF-the master bender. Curr. Biol. 7, R252-R254.

Tse-Dinh, Y.-C. 1985 Regulation of the Escherichia coli DNA topoisomerase I gene by DNA supercoiling. Nucl. Acids Res. 13, 4751-4763.

Uchiya, K., Barbieri, M. A., Funato, K., Shah, A. H., Stahl, P. D. \& Groisman, E. A. 1999 A Salmonella virulence protein that inhibits cellular trafficking. EMBO f. 18, 3924-3933.
Ussery, D. W., Hinton, J. C. D., Jordi, B. J. A. M., Granum, P. E., Seirafi, A., Stephen, R. J., Tupper, A. E., Berridge, G., Sidebotham, J. M. \& Higgins, C. F. 1994 The chromatinassociated protein H-NS. Biochimie 76, 968-980.

Valdivia, R. H. \& Falkow, S. 1997 Fluorescence-based isolation of bacterial genes expressed within host cells. Science 277, 2007-2011.

Van Workum, M., Van Dooren, S. J. M., Oldenburg, N., Molenaar, D., Jensen, P. R., Snoep, J. L. \& Westerhoff, H. V. 1996 DNA supercoiling depends on the phosphorylation potential in Escherichia coli. Mol. Microbiol. 20, 351-360.

Waldburger, C. D. \& Sauer, R. T. 1996 Signal detection by the PhoQ sensor-transmitter: characterization of the sensor domain and a response-impaired mutant that identifies ligandbinding determinants. 7. Biol. Chem. 271, 26 630-26 636.

Wang, J. C. 1971 Interaction between DNA and an Escherichia coli protein $\omega$. 7. Mol. Biol. 55, 523-533.

Williams, R. M. \& Rimsky, S. 1997 Molecular aspects of the E. coli nucleoid protein, H-NS: a central controller of gene regulatory networks. FEMS Microbiol. Lett. 156, 175-185.

Wilson, J. A., Doyle, T. J. \& Gulig, P. A. 1997 Exponentialphase expression of $s p v A$ of the Salmonella typhimurium virulence plasmid: induction in intracellular salts medium and intracellularly in mice and cultured mammalian cells. Microbiology 143, 3827-3839.

Wolf, S. G., Frenkiel, D., Arad, T., Finkel, S. E., Kolter, R. \& Minsky, A. 1999 DNA protection by stress-induced biocrystallization. Nature 400, 83-85.

Wu, H.-Y., Shyy, S., Wang, J. C. \& Liu, L. F. 1988 Transcription generates positively and negatively supercoiled domains in the template. Cell 53, 433-440.

Yamada, H., Yoshida, T., Tanaka, K. I., Sasakawa, C. \& Mizuno, T. 1991 Molecular analysis of the Escherichia coli hns gene encoding a DNA-binding protein, which preferentially recognises curved DNA sequences. Mol. Gen. Genet. 230, 332-336.

Zhang, A., Rimsky, S., Reaban, M. E., Buc, H. \& Belfort, M. 1996 Escherichia coli protein analogs StpA and H-NS: regulatory loops, similar and disparate effects on nucleic acid dynamics. EMBO F. 15, 1340-1349. 